\title{
Woodcock-Johnson Tests of Cognitive
}

\section{Abilities}

National Cancer Institute

\section{Source}

National Cancer Institute. Woodcock-Johnson Tests of Cognitive Abilities. NCI Thesaurus.

Code C115129.

A comprehensive, individually administered cognitive assessment that identifies strengths and weaknesses in cognitive abilities, processes, and academic performance. 